\title{
GÄSTREDAKTÖRERNAS FÖRORD
}

\section{Queer nordisk *bygd}

NÄR VI BLICKADE ut över raderna av tillfälligt uppställda stolar på Västerbottens museum i Umeå den 2 april 20I7, möttes vi av en publik i tårar. Framför oss spelade Riksteatern föreställningen Landet Inuti, som är baserad på intervjuer med hbtq-personer som återvänt, flyttat till eller aldrig lämnat landsbygden. Hos vissa i publiken rann tårarna stilla nerför kinderna. Andra begravde ansiktet i händerna.

Är det bara i staden jag kan bli hel? Måste jag flytta till stan för att få leva som jag vill? Alla flyttar ju - har jag ens ett val? Du ska få ett liv i storstan, säger de, här finns ingen framtid för en sån som du.

(Landet Inuti, Riksteatern u.å.)

Landet Inuti och responsen från publiken på Västerbottens museum, utgör exempel på vilka erfarenheter och berättelser som kan framträda när sökljuset riktas mot queera erfarenheter och livsberättelser från andra platser än storstäderna och de känslor som detta kan väcka.

Idén till detta temanummer uppstod när vi gästredaktörer under våren 2016 började samtala om våra respektive forskningsintressen och pågående forskningsprojekt som på olika sätt berör just relationerna mellan queer och olika former av lands- och glesbygd, frågor som också tematiserades i föreställningen Landet Inuti. Vårt samtal berörde bland annat de känslomässiga reaktioner som plats och identitet tycktes 
utlösa. Vi kom snart även in på tendensen inom queerforskningen till en till synes oreflekterad storstadscentrering och vi kände en önskan att ta del av fler berättelser från lands- och glesbygd. Då merparten av tidigare forskning, som berör geografiska kontexter bortom storstadsmiljöer, främst berör nordamerikanska (se ex.vis Gray 2009; Herring 20I0; Kazyak 20II; 20I2; Detamore 2013; Johnson 2013; Gray m.fl. 2or6) och australiensiska förhållanden (se ex.vis Gorman-Murray m.fl. 2008; Gorman-Murray 2009; Waitt och Johnston 2013), var vi också nyfikna på, och angelägna om, att få ta del av ytterligare forskning om queer och landsbygder som, likt våra respektive pågående studier om Pridefestivaler bortom storstadsområdena ${ }^{\mathrm{I}}$ (Anna Olovsdotter Lööv) och meningsskapande kring identitet, plats och sociala medier med norra Sverige som utgångspunkt ${ }^{2}$ (Evelina Liliequist), är situerad i en nordisk kontext.

Tidigare forskning om queer och landsbygder i en nordisk kontext har synliggjort en komplexitet som går bortom enkla förståelser av den "intoleranta" lands- och glesbygden och hbtq-personers "flykt" till storstäderna, både i representationer av hbtq-liv (Björklund 2010; 2013) och hbtq-personers vardagsverklighet (Sorainen 20I4; Siverskog 2016). Behovet av att situera queermigration till metropolerna $i$ tid och rum har tydliggjorts (Wimark 20I4; Siverskog 20I6), samt att livet bortom storstäderna ser olika ut i olika nordiska kontexter, bland annat beroende på skillnader i lagstiftning som påverkar hbtq-personers liv (se ex.vis Sorainen 20I4). Storstadens queera glans har också mattats i forskning om hbtq-personers skilda villkor som visat hur stadens möjligheter är ojämlikt fördelade och inte varken gäller, eller appellerar till, alla (se ex.vis Bell och Binnie 2004; Wimark 2014; Haritaworn 2015).

Vår ambition med detta temanummer av lambda nordica är att samla och presentera forskning som kan fördjupa förståelsen av queer och, det som vi i detta temanummer väljer att kalla, *bygd i Norden och därigenom bidra till ett (förhoppningsvis) växande forskningsfält av nordiska rurala queerstudier. Skälen till att fokusera den nordiska *bygdkontexten är en vilja både att synliggöra en specifik geopolitisk kontext och att samla forskning som på olika sätt relaterar till den. Samtidigt 
måste vi också ställa oss frågan vilka de geopolitiska implikationerna är av att ställa frågor om queer i Norden (Dahl 2oı I, se även Dahl m.fl. 2016). Då delar av Norden utgörs av koloniserad samisk mark (Andersson och Cocq 2016), måste även koloniala strukturer och de historiska och pågående konflikter och maktrelationer som kolonisering medför, erkännas och diskuteras. Vilka berättelser får representera nordisk *bygd? Vilka berättelser berättar vi? Och vilka är "vi"?

\section{*bygd: Ett sätt att queera förståelsen av plats}

Begreppet *bygd används i dag i aktivistiska nätverk, som exempelvis Queer*bygd, ${ }^{3}$ dels som ett paraplybegrepp för olika typer av bygder, exempelvis glesbygd, landsbygd och obygd, dels för att ifrågasätta, och skapa gemenskaper bortom, geografiska gränser. Likt relationen mellan queeraktivism och queerteori utgör den aktivistiska användningen av *bygd en inspirationskälla för utvecklandet av nya analytiska begrepp. Genus- och queerforskaren Ulrika Dahl (20I I, I55) påtalar behovet av att inom queerforskning, "continue to queer our conceptual and territorial maps of both scholarship and activism", för att inte riskera att ojämlika maktrelationer naturaliseras. Mot denna bakgrund föreslår vi att *bygd skulle kunna fungera som ett queerande analytiskt begrepp i forskning om geografiska områden bortom storstäder.

Trans*- och utbildningsforskaren Z Nicolazzo (2017) poängterar att asterisken kan utgöra en textuell störning - ett performativt brott med normativa förståelser av vad trans* kan vara. Vi menar att *bygd potentiellt sett kan få en liknande betydelse för innebörder och förståelser av icke-urbana platser. Likt bruket av asterisk i trans* så rymmer *bygd en önskan om öppenhet och odefinierade gränser. Vi är dock medvetna om att lika väl som bruket av asterisk kan möjliggöra inkludering och gemenskap, riskerar det också att överbetona likhet och dölja skillnader och maktrelationer mellan olika platser som kan rymmas $i$ *bygdbegreppet. Till exempel varierar befolkningsmängden. Givetvis finns även stora kulturella och materiella skillnader, där närhet och avstånd påverkar hur livet kan organiseras och vilka platser som är möjliga att nå, och av vem. Avstånd är i mångt och mycket en fråga om infrastruk- 
tur, som i förlängningen kan ses som en materialisering av politiska villkor. Att exempelvis växa upp i "Fucking Åmål” kan alltså vara något helt annat än att göra detsamma i "Fucking Storuman".

Vi vill betona att *bygd som analytiskt begrepp ska läsas i relation till en tradition av feministisk transversal politik (Yuval-Davis I999) där den samhörighet mellan platser som begreppet kan fånga ska förstås som skapad genom transversala dialoger där deltagarna/ platserna förstår sina egna positioner för att empatiskt kunna skifta till en annans position. Med *bygd-begreppet vill vi alltså undersöka relationer mellan platser bortom storstäderna och låta gemenskaper byggas genom transversala dialoger mellan platser. Vi menar att *bygd-begreppet kan möjliggöra ett synliggörande och påtalande av territoriella maktrelationer i syfte att förändra dem. Trots det är det dock återigen relevant och nödvändigt att betänka vilka berättelser som får representera *bygd, och vilka "vi" är som befolkar *bygden. Som Margareta Lindholm (1996, 43) formulerar det i ett resonemang utifrån Judith Butler, "[i]dentitet är inte bara inneslutande utan också med nödvändighet uteslutande”. På vilka grunder kvalar en plats in som *bygd? Och vem kan åberopa en *bygd-identitet? Här blir koloniala strukturer och dess effekter än viktigare att beakta - vems *bygd är det vi talar om egentligen? På vilka grunder, och med vilka medel, kan en plats "tas tillbaka" och utropas som ens egen?

Med detta sagt ser vi en möjlighet att i framtida forskning utforska potentialen i begreppet *bygd att queera förståelsen av plats och (relationerna mellan) olika specifika geografiska kontexter.

I temanumrets We're Here-essä "Ett forskarsamtal om queer och *bygd", använder vi *bygd som ett paraplybegrepp och gör ett försök att tillämpa *bygd analytiskt. Essän kan läsas som ett uttryck för ett försök till, och en vilja att, resonera från den plats som *bygd möjliggör.

\section{Temanumrets innehåll: *bygden som queer plats}

Gemensamt för artikelbidragen i detta temanummer är att de på olika sätt ställer frågor om *bygden som queer plats, och som möjliggörande plats för queera liv och praktiker. 
I "'DRA ÅT SKOGEN': Eva-Stina Byggmästars naturqueera framtidsestetik", undersöker litteraturvetaren Jenny Jarlsdotter Wikström hur skogen och trädgården framträder som poetiska och politiska idyller i Eva-Stina Byggmästars poesi. Kan rurala miljöer, som naturen och skogen vara ett paradis för queers i verkligheten, lika väl som i dikten? Jarlsdotter Wikström använder även Byggmästars lyrik, och dess naturqueera estetik, som utgångspunkt för att utforska föreställda motsättningar mellan queerteori och ekokritik och hur dessa potentiellt kan överbryggas.

I folkloristen Catarina Harjunens bidrag "Queer Perspectives on Erotic Human-Supernatural Encounters in Finland-Swedish Folk Legends”, är det skogsrået och andra naturväsen som befolkar skogen. I fokus står erotiska möten mellan människor och naturväsen i finlandssvenska folksägner. Genom en tillämpning av queerteori och posthumanistisk teori problematiserar och utmanar Harjunen sägnernas idéer om normativ kvinnlig och manlig sexualitet. I en queer närläsning av materialet ifrågasätts även föreställningar om den binära uppdelningen natur/kultur, samt dikotomins relation till sexualitet.

"Obygden", som plats och möjligt queert koncept utforskas i etnologen Angelika Sjöstedts bidrag "'Längtan efter något som man anar, men inte vet riktigt vad det är ens': Att läsa obygd queer". Med utgångspunkt i sin mormors mors dagbok, som beskriver livet i det hon kallar "obygden", skapar Sjöstedt länkar mellan queer och obygd genom dess förpassning till periferierna, och frågar sig om obygd likt queer kan symbolisera motstånd mot det (hetero)normativa.

I We're Here "Ett forskarsamtal om queer och *bygd", får frågor om samtida hbtq-personers *bygd-erfarenheter utrymme. Essän bygger på ett samtal mellan kulturgeografen Thomas Wimark och temanumrets redaktörer, etnologen Evelina Liliequist och genusvetaren Anna Olovsdotter Lööv. Numrets tema, queer och *bygd i en nordisk kontext, behandlas med utgångspunkt i deltagarnas egen forskning. Samtalet handlade om allt från den livskraftiga berättelsen om att "komma ut och fly till storstaden", till hur geografiska gränser luckrades upp i samband med internets intåg och hur lokala geografiska kontexter senare 
har (åter)aktualiserats i geolokaliserade dejtingappar. Innebörden av "queera platser" och vilka platser som egentligen kan förstås som queera och betraktas som betydelsefulla för hbtq-communityt, diskuterades också. Dessutom behandlades behovet av, och svårigheterna med, att tillämpa ett perspektiv där storstaden inte utgör en självklar utgångseller referenspunkt. Hur kan forskarblicken se bortom det urbana tolkningsföreträdet - och vad blir då synligt?

W're Here-samtalet tar främst utgångspunkt i forskning om levda erfarenheter och utgör således ett komplement till temanumrets artikelbidrag som bygger på textbaserade representationer av *bygden i poesi, folksägner, och en dagbok. Temanumret bidrar därmed till kunskap både om *bygdens platser och queera erfarenheter från *bygd, men även till hur identitet och plats har betydelse för varandra.

Avslutningsvis hoppas vi att den queera *bygden tar plats inom akademin och att kunskapsproduktionen fortsätter att breddas utifrån erfarenheter från olika horisonter. Detta är vårt bidrag.

EVELINA LILIEQUIST och ANNA OLOVSDOTTER LÖÖV, GÄSTREDAKTÖRER

\section{REFERENSER}

Andersson, Daniel, och Coppélie Cocq. 2or6. "Från kolonisation till gruvexploatering: Nyttoperspektiv på naturen i Sápmi förr och nu." Kulturella perspektiv 25.I:42-9.

Bell, David, och Jon Binnie. 2004. ”Authenticating Queer Space: Citizenship, Urbanism and Governance." Urban Studies 41.9:1807-20.

Björklund, Jenny. 2010. "Queering the Small Town: Lukas Moodysson's Film Show Me Love." Women's Studies 39.1:37-5 I.

-. 2013. "Coming Out, Coming In: Geographies of Lesbian Existence in Contemporary Youth Novels." I Sexuality, Rurality, and Geography, redaktörer Andrew GormanMurray, Barbara Pini och Lia Bryant, I38-48. Lanham: Lexington.

Dahl, Ulrika. 20ı r. "Queer in the Nordic Region: Telling Queer (Feminist) Stories.” I Queer in Europe: Contemporary Case Studies, redaktörer Lisa Downing och Robert Gillett, I43-57. Farnham: Ashgate. 
Dahl, Ulrika, Marianne Liljeström, och Ulla Manns. 20I6. The Geopolitics of Nordic and Russian Gender Research 1975-2005. Huddinge: Södertörns högskola.

Detamore, Mathias. 20r3. "Queering the Hollow: Space, Place, and Rural Queerness." I Sexuality, Rurality, and Geography, redaktörer Andrew Gorman-Murray, Barbara Pini och Lia Bryant, 8I-93. Lanham: Lexington.

Gorman-Murray, Andrew. 2009. "Intimate Mobilities: Emotional Embodiment and Queer Migration.” Social E Cultural Geography ro.4:44I-6o.

Gorman-Murray, Andrew, Gordon Waitt, och Chris Gibson. 2008. ”A Queer Country?: A Case Study of the Politics of Gay/Lesbian Belonging in an Australian Country Town." Australian Geographer 39.2:17 I-9I.

Gray, Mary L. 2009. Out in the Country: Youth, Media, and Queer Visibility in Rural America. New York: New York University Press.

Gray, Mary L., Brian J. Gilley, och Colin R. Johnson. 2016. Queering the Countryside: New Frontiers in Rural Queer Studies. New York: New York University Press.

Haritaworn, Jin. 2015. Queer Lovers and Hateful Others: Regenerating Violent Times and Places. London: Pluto.

Herring, Scott. 2010. Another Country: Queer Anti-Urbanism. New York: New York University Press.

Johnson, Colin R. 2013. Just Queer Folks: Gender and Sexuality in Rural America. Philadelphia: Temple University Press.

Kazyak, Emily. 2or r. "Disrupting Cultural Selves: Constructing Gay and Lesbian Identities in Rural Locales." Qualitative Sociology 34.4:56I-8I.

-. 20I 2. "Midwest or Lesbian?: Gender, Rurality, and Sexuality." Gender E Society 26.6:825-48.

Liliequist, Evelina. (Kommande). "Digitala förbindelser: Hbtq-personers meningsskapande i relation till sociala medier, identitet och plats i norra Sverige." Avhandling, Umeå universitet.

Lindholm, Margareta. 1996. "Vad har sexualitet med kön att göra?" lambda nordica $2.3-4: 38-53$.

Niccolazzo, Z. 2017. "To Use or Not to Use the Asterisk." Trans* resilience blog, r februari. https://znicolazzo.weebly.com/trans-resilience-blog/-to-use-or-not-to-use-the-asterisk.

Riksteatern. u.å. "Landet Inuti." https://www.riksteatern.se/landetinuti.

Siverskog, Anna. 20I6. "Queera livslopp: Att leva och åldras som lhbtq-person i en heteronormativ värld." Avhandling, Linköpings universitet.

Sorainen, Antu. 2014. "Queer Personal Lives, Inheritance Perspectives, and Small Places." lambda nordica I9.3-4:3 I-54.

Waitt, Gordon, och Lynda Johnston. 2013. 'It Doesn't Even Feel Like It's Being Processed by Your Head': Lesbian Affective Home Journeys to and within Townsville, Queensland, Australia." I Sexuality, Rurality, and Geography, redaktörer Andrew Gorman-Murray, Barbara Pini och Lia Bryant, I23-37. Lanham: Lexington. 
Wimark, Thomas. 2or 4. "Beyond Bright City Lights: The Migration Patterns of Gay

Men and Lesbians." Avhandling, Stockholms universitet.

Yuval-Davis, Nira. I999. "What Is 'Transversal Politics'?” Soundings I 2:94-8.

\section{NOTER}

I. Löövs forskningsprojekt, Decentraliserad stolthet: En etnografisk studie av Pridefestivaler bortom Sveriges storstäder, är finansierat av ett mobilitetsstöd från Formas (2017-2018).

2. Liliequists avhandling har den preliminära titeln Digitala förbindelser: Hbtqpersoners meningsskapande i relation till sociala medier, identitet och plats i norra Sverige. Beräknas utkomma år 2020.

3. Queer*bygd presenterar sig som "ett nätverk av människor och grupper som arbetar queert/med icke-norm på landsbygd/i icke-storstäder eller vill dela, utforska, utveckla och diskutera queera bygder". Dess syfte är att "skapa rum för konkreta aktiviteter och vara ett forum för diskussion kring vad ett queert liv på landsbygden, glesbygden, obygden eller på en mindre ort kan vara och innebära”. Nätverket organiseras bland annat via en grupp på Facebook och en blogg, https:/queerbygd.wordpress.com/. 